\title{
Relação entre biofábrica e porosidade, coquinas da Formação Morro do Chaves (Barremiano/Aptiano), Bacia de Sergipe-Alagoas, NE-Brasil
}

\author{
Biofabric and porosity relationship in coquinas, Morro do Chaves
}

Formation (Barremian/Aptian), Sergipe-Alagoas Basin, Brazil-NE

\author{
Guilherme Furlan Chinelatto ${ }^{1}$ (D), Michelle Chaves Kuroda ${ }^{1}$ (D), Alexandre Campane Vidal ${ }^{1}$ (D) \\ 1 Universidade Estadual de Campinas - UNICAMP, Departamento de Geologia e Recursos Naturais, Centro de Estudos do \\ Petróleo (DGRN - CEPETRO), Rua 6 de Agosto, 50, $1^{\circ}$ andar, Reitoria V, CEP 13083-873, Barão Geraldo, Campinas, SP, BR \\ (gfchinelatto@gmail.com; mckuroda@gmail.com; vidal@ige.unicamp.br)
}

Recebido em 10 de novembro de 2017; aceito em $1^{\circ}$ de outubro de 2018

\begin{abstract}
Resumo
As coquinas da Formação Morro do Chaves são consideradas rochas análogas aos reservatórios da fase rifte do pré-sal nas bacias de Campos e Santos, são compostas principalmente por conchas e fragmentos de bivalves revelando uma grande variedade da biofábrica e do sistema poroso que possibilita o uso da tafonomia para relacionar o ambiente deposicional dessas rochas com as características de porosidade. Os principais atributos tafonômicos abordados nesse trabalho são: orientação das valvas; empacotamento das conchas; granulometria e seleção; e grau de fragmentação, abrasão e arredondamento. A interpretação dos dados teve como objetivo agrupar as amostras com relação às diferentes características tafonômicas e a porosidade, tendo como ferramenta auxiliar o método de redes neurais artificias (Self-Organization Map - SOM). A análise dos dados resultou em três agrupamentos: A1 com altos valores de porosidade (entre 11 e 23\%), cujas características tafonômicas revelam ambientes de alta energia; A2 com valores intermediários de porosidade (entre 7 e $15 \%$ ), cujas características tafonômicas indicam um ambiente de transição entre alta e baixa energia; por fim, o grupo A3 com menores valores de porosidade (entre 0 e 7\%), cuja tafonomia indica ambientes de baixa energia. Como resultado final, as características tafonômicas revelam a energia do ambiente deposicional e é possível associar ambientes de alta energia com as altas porosidades para as coquinas da Formação Morro do Chaves.
\end{abstract}

Palavras-chave: Tafonomia; Coquina; Porosidade; Formação Morro do Chaves.

\begin{abstract}
Coquinas of Morro do Chaves Formation are analogous rocks of pre-salt reservoirs of Campos and Santos basins; they are mainly composed by shells and fragments of bivalves that present a great variability of biofabric and porous system, which allows the use of taphonomy to relate their depositional environment. The main taphonomic attributes in this work are: valve orientation; shell packing; granulometry and selection; degree of fragmentation, abrasion and roundness. The interpretation of data had as objective grouping the samples according to different taphonomic patterns and porosity, using the artificial neural networks method (Self-Organization Map - SOM) as auxiliary tool. The analysis of data resulted in 3 clusters: A1 with high porosity values (between 11 and 23\%) whose taphonomic characteristics reveal a high energy environment; A2 with intermediate values of porosity (between 7 and 15\%) whose taphonomic characteristics indicate a transition environment between high and low energy; finally,group A3 with lower values of porosity (between 0 and $7 \%$ ) whose taphonomy indicates low energy environments. As a final result, the taphonomic characteristics reveal the energy of the depositional environment and it is possible to associate high energy environments with the high porosities for the Coquinas of the Morro do Chaves Formation.
\end{abstract}

Keywords: Taphonomy; Coquina; Porosity; Morro do Chaves Formation. 


\section{INTRODUÇÃO}

Os reservatórios carbonáticos constituem aproximadamente $50-60 \%$ de toda reserva de hidrocarbonetos no mundo (Ramakrishnan et al., 2001; Bust et al., 2011; Burchette, 2012), são de uma natureza diversa com relação a sua formação e podem apresentar um complexo sistema poroso. De maneira geral, esses reservatórios se diferenciam dos siliciclásticos devido ao tipo de produção de sedimentos e da reatividade química de minerais carbonáticos (Ehrenberg e Nadeau, 2005), resultando em rochas com grande diversidade textural e petrofísicas.

Nas últimas décadas, reservas de petróleo em carbonatos foram encontradas em águas ultraprofundas na margem continental brasileira, abrangendo as bacias de Campos e Santos (Chang et al., 2008; Riccomini et al., 2012). Alguns desses reservatórios foram descobertos abaixo da sequência de evaporitos, denominados de pré-sal, e são compostos por rochas carbonáticas lacustres, predominantemente coquinas e microbialitos (Baumgarten et al., 1988; Carvalho et al., 2000; Riccomini et al., 2012; Muniz e Bosence, 2015). $\mathrm{O}$ acesso a essas rochas é feito por meio de furos de sondagens por conta da ausência de afloramentos em superfície e, por esse motivo, o uso de depósitos análogos pode auxiliar na compreensão desses reservatórios. As coquinas da Formação Morro do Chaves são consideradas análogas às coquinas do pré-sal na Bacia de Campos (Abrahão e Warme, 1990). Entender como se formaram, como se distribuem e quais os principais fatores que controlam suas características petrofísicas pode auxiliar na exploração das reservas do pré-sal.

A caracterização das propriedades petrofísicas em coquinas é um grande desafio para a indústria petrolífera devido sua heterogeneidade geológica referente aos processos de sedimentação (Carvalho et al., 2000; Thompson et al., 2015; Tavares et al., 2015; Corbett et al., 2016), além das alterações provocadas pela diagênese (Tavares et al., 2015; Corbett et al., 2016).

De maneira geral, os trabalhos que buscam relacionar as características geológicas e petrofísicas, em arenitos e carbonatos, têm como foco a caracterização da porosidade e da permeabilidade em função de características texturais, deposicionais e diagenéticas (Scherer, 1987; Ferm et al., 1993; Makhloufi et al., 2013).

A tafonomia é um ramo da ciência que estuda os processos de fossilização, com enfoque no habitat, nos processos de transporte, na sedimentação e na diagênese dos organismos. Por meio das características tafonômicas e sedimentares, é possível interpretar as condições de energia e paleoambientais envolvidas nos processos de sedimentação.

Com referência às coquinas, as assinaturas tafonômicas são utilizadas de forma rotineira para a caracterização geológica dessas rochas, sendo importante as informações sobre tamanho, orientação, fragmentação e abrasão das conchas, como também quantidade de matriz (Kidwell, 1986; Kidwell et al., 1986; Kidwell e Holland, 1991; Fürsich e Oschmann, 1993).

Como forma de avaliar a correlação entre propriedades geológicas e petrofísicas, este trabalho buscou avaliar a influência de algumas assinaturas tafonômicas sobre a porosidade macro (amostra de mão) e meso (lâmina delgada) de amostras de coquinas da Formação Morro do Chaves.

\section{CONTEXTO GEOLÓGICO REGIONAL E ÁREA DE ESTUDO}

A Formação Morro do Chaves está inserida na Bacia de Sergipe-Alagoas, uma bacia da margem passiva brasileira, localizada na região Nordeste do Brasil entre os paralelos 9 e $11^{\circ}$ sul. O limite norte da bacia é atribuído ao Alto Maragogi e o sul, ao sistema de falhas Vaza Barris; conta com uma área de aproximadamente 33 mil km²: 13 mil km² em sua área emersa e 20 mil km² referente à submersa (Feijó, 1994).

A bacia desenvolveu-se durante a separação do supercontinente Gondwana com diferentes estágios de evolução tectônica. As fases de separação da bacia se deram em sinéclise, pré-rifte, rifte e margem passiva (drifte) (Campos Neto et al., 2007). A Formação Morro do Chaves depositou-se durante a fase rifte da bacia.

Essa formação é constituída por sedimentos carbonáticos do tipo "coquina" e siliciclásticos representados por folhelhos e arenitos, caracterizando um sistema lacustre desenvolvido em um semi-gráben durante a fase rifte (Figueiredo, 1981; Feijó, 1994; Souza-Lima et al., 2002; Campos-Neto et al., 2007).

No intervalo estratigráfico referente à fase rifte, a bacia é compartimentada por um sistema em meio-gráben mergulhando para sudeste, sendo constituída de um conjunto de falhas normais N-S interceptado por falhas E-W e NE-SW, resultando em uma configuração NE-SW en-échelon (Ojeda e Fugita, 1976 apud Souza-Lima et al., 2002; Lana e Milani, 1986; Van Der Ven et al., 1989).

A bacia conta com altos e baixos estruturais, nos quais os altos são de dois tipos: horsts e estruturas dômicas. Os horsts são alongados na direção N-S cujas falhas separam o meio-gráben, as estruturas dômicas se mostram arqueadas como produto de esforços associados ao cisalhamento (Lana e Milani, 1986; Lana, 1990).

O preenchimento sedimentar ocorreu por meio das diferentes fases tectônicas que atuaram na bacia; cada compartimento sofreu processos de soerguimento ou subsidência de modo desigual ao longo do tempo, o que resultou em uma distribuição espacial bastante complexa das unidades estratigráficas (Aquino e Lana, 1990). 


\section{Formação Morro do Chaves}

A Formação Morro do Chaves apresenta coquinas de bivalves como litologia predominante, intercaladas com folhelhos e arenitos depositados em diferentes pulsos tectônicos (Campos Neto et al., 2007). Essas rochas carbonáticas são interpretadas como depósitos lacustres rasos em razão da ausência de fósseis marinhos (Petri, 1962; Figueiredo, 1981) e da ocorrência de ostracodes não marinhos (Hourcqia africana). No entanto, estudos recentes sugerem certa influência marinha por conta da descoberta de fósseis típicos desse ambiente (Gallo et al., 2010; Garcia, 2012, 2016; Thompson, 2013; Garcia et al., 2018). Os depósitos foram acumulados em altos estruturais em um sistema de rampa suave, onde extensas camadas de bivalves foram depositadas em ambiente raso e de alta energia (Figueiredo, 1981; Kinoshita, 2010; Tavares et al., 2015; Chinelatto et al., 2018).

O contato superior entre a Formação Morro do Chaves e a Formação Coqueiro Seco é erosivo ou gradacional para depósitos clásticos na sub-bacia de Sergipe, enquanto na sub-bacia de Alagoas é marcado pela ocorrência de um calcário gredoso (chalky). Em direção à margem da bacia, a unidade migra lateralmente para os depósitos da Formação Rio Pitanga (Schaller, 1969).

As coquinas da Formação Morro do Chaves têm sido alvo de diversos estudos (Kinoshita, 2010; Belila, 2014; Tavares et al., 2015; Corbett et al., 2016; Menezes et al., 2016; Chinelatto et al., 2018). Entre esses trabalhos, alguns são voltados à utilização de dados tafonômicos para interpretação do ambiente deposicional e explicar a evolução dos depósitos (Tavares et al., 2015; Chinelatto et al., 2018).

Com a interpretação de tafofácies, esses trabalhos ilustram a evolução das coquinas como depósitos rasos, profundos e de tempestade variando suas características texturais. As coquinas interpretadas como de ambiente raso não apresentam material argiloso, são compostas por conchas de bivalves e fragmentos de conchas; os bioclastos são arranjados preferencialmente concordantes com o acamamento e apresentam um empacotamento denso. É possível observar conchas com sinais de abrasão e a micritização dos bioclastos é baixa. Acumulações profundas apresentam matriz argilosa, diferente das coquinas rasas; estas apresentam menor concentração de bioclastos fragmentados, caracterizando um empacotamento frouxo a disperso. É comum a ocorrência de valvas fechadas e bordas bem micritizadas. Os depósitos de tempestade podem ou não conter matriz argilosa, as conchas de bivalves não apresentam uma orientação preferencial e, de maneira geral, os bioclastos são desarticulados, embora valvas fechadas possam ocorrer. Fragmentos de conchas são comuns e o empacotamento pode variar de frouxo a denso. Nesse tipo de acumulação, é comum a ocorrência de superfícies erosivas na base.

\section{MATERIAIS E MÉTODOS}

\section{Descrição de afloramento e coleta de amostras}

O afloramento utilizado para o estudo está localizado na pedreira CIMPOR Cimentos, na cidade de São Miguel dos Campos, Alagoas, com acesso por meio da Rodovia Governador Mario Covas (AL-220), km 135. A cava da pedreira tem extensão norte-sul de aproximadamente $1 \mathrm{~km}$ e seção vertical próxima a $60 \mathrm{~m}$. O embasamento na área de estudo compreende paragnaisses e migmatitos do Complexo Arapiraca. Depósitos sedimentares pós-proterozoicos do Grupo Coruripe são aflorantes, principalmente a Formação Coqueiro Seco (Cretáceo Inferior), depositada concomitantemente à Formação Morro do Chaves. Acima dessas unidades, depósitos do Grupo Barreiras ocorrem assim como sedimentos aluvionares do quaternário (Figura 1).

$\mathrm{Na}$ etapa de campo, foram levantadas seções geológicas identificando as principais litologias utilizando da classificação de Dunham (1962) e Embry e Klovan (1971), onde diferentes fácies de coquinas foram amostradas e encaminhadas ao laboratório. As características utilizadas para diferenciar os tipos de coquina foi com relação ao estado de preservação das conchas, à quantidade de matriz e à qualidade do espaço poroso. As amostras são representativas da variabilidade da biofábrica das coquinas encontrada em afloramento, principalmente com relação ao grau de fragmentação e orientação das conchas, à granulometria média e ao tipo de matriz. Para esse trabalho foram coletadas 20 amostras com volume próximo a $2.000 \mathrm{~cm}^{3}$ cada e orientadas em relação ao acamamento e à direção do topo.

\section{Análise de laboratório: descrição petrográfica e classificação da biofábrica}

A análise petrográfica se baseou na descrição de lâminas delgadas e na análise de imagens escaneadas de rocha, onde foi possível desenhar e quantificar as conchas observadas. Esse processo foi realizado utilizando do software editor de imagem Inkscape. As imagens foram obtidas por meio de cortes perpendiculares em relação ao plano do topo/base de cada amostra e posteriormente analisadas em escala macro de alta resolução (1.200 dpi).

Para a classificação da biofábrica foram utilizados os parâmetros sugeridos por Kidwell e Holland (1991) e Kidwell (1991) de granulometria, seleção, densidade de empacotamento das conchas, orientação das valvas e grau de fragmentação.

Os parâmetros tafonômicos foram quantificados a partir das imagens digitalizadas da rocha; 50 - 100 bioclastos vizinhos/adjacentes foram computados para o levantamento dos dados. A análise petrográfica foi utilizada 
também para a obtenção de parâmetros tafonômicos, principalmente na determinação do grau de fragmentação e abrasão das conchas.

\section{Orientação das valvas}

A classificação da orientação das valvas segue o modelo proposto por Kidwell (1991), que a divide nas seguintes categorias:

1. concordante;

2. oblíquo;

3. vertical em relação ao plano de acamamento.

Dessa forma, conchas que apresentam concavidade voltada para baixo ou para cima e são paralelas ao acamamento são consideradas concordantes; quando dispostas inclinadas, são consideradas oblíquas; e quando inclinadas próximas a 90 graus ao acamamento, são definidas como verticais (Figura 2A). Biofábrica que apresentasse conchas empilhadas ou aninhadas (nested, em inglês) também foi mencionada, no entanto não foi quantificada individualmente.

Rochas que apresentam mais de $45 \%$ de conchas concordantes ao acamamento foram classificadas como coquinas com biofábrica concordante, e as demais como coquinas com biofábrica caótica.

\section{Granulometria, seleção e densidade de conchas}

De acordo com Kidwell e Holland (1991), a seleção varia entre três parâmetros: bem selecionada, bimodal e mal selecionada, dentro da escala granulométrica phi (Figura 2B). Rochas bem selecionadas são aquelas que apresentam por volta de $80 \%$ da concentração de bioclastos entre $1-2$ escalas adjacentes de granulometria. Seleção bimodal pode aparentar uma boa seleção, no entanto apresentam ocorrências de granulometrias muito distantes umas das outras dentro da escala granulométrica, por exemplo, uma rocha com domínio de granulometria em -1 e -4 phi seria considerada uma distribuição bimodal. Rochas com má seleção são aquelas que apresentam $80 \%$ de sua distribuição granulométrica entre 3 ou mais classes.

Quanto à densidade de conchas, Kidwell e Holland (1991) classificam como empacotamento denso, frouxo e disperso (Figura 2C). O empacotamento denso representa rochas bioclasto suportadas, onde o contato bioclasto-bioclasto é comum, normalmente observado em rudstones e grainstones. O empacotamento frouxo representa rochas cujo contato bioclasto-bioclasto é menor e o espaçamento entre eles é pequeno (menor que o seu tamanho de corpo); normalmente, os bioclastos encontram-se flutuantes na matriz e podem ser representados por packstones e wackestones. O empacotamento disperso representa rochas onde

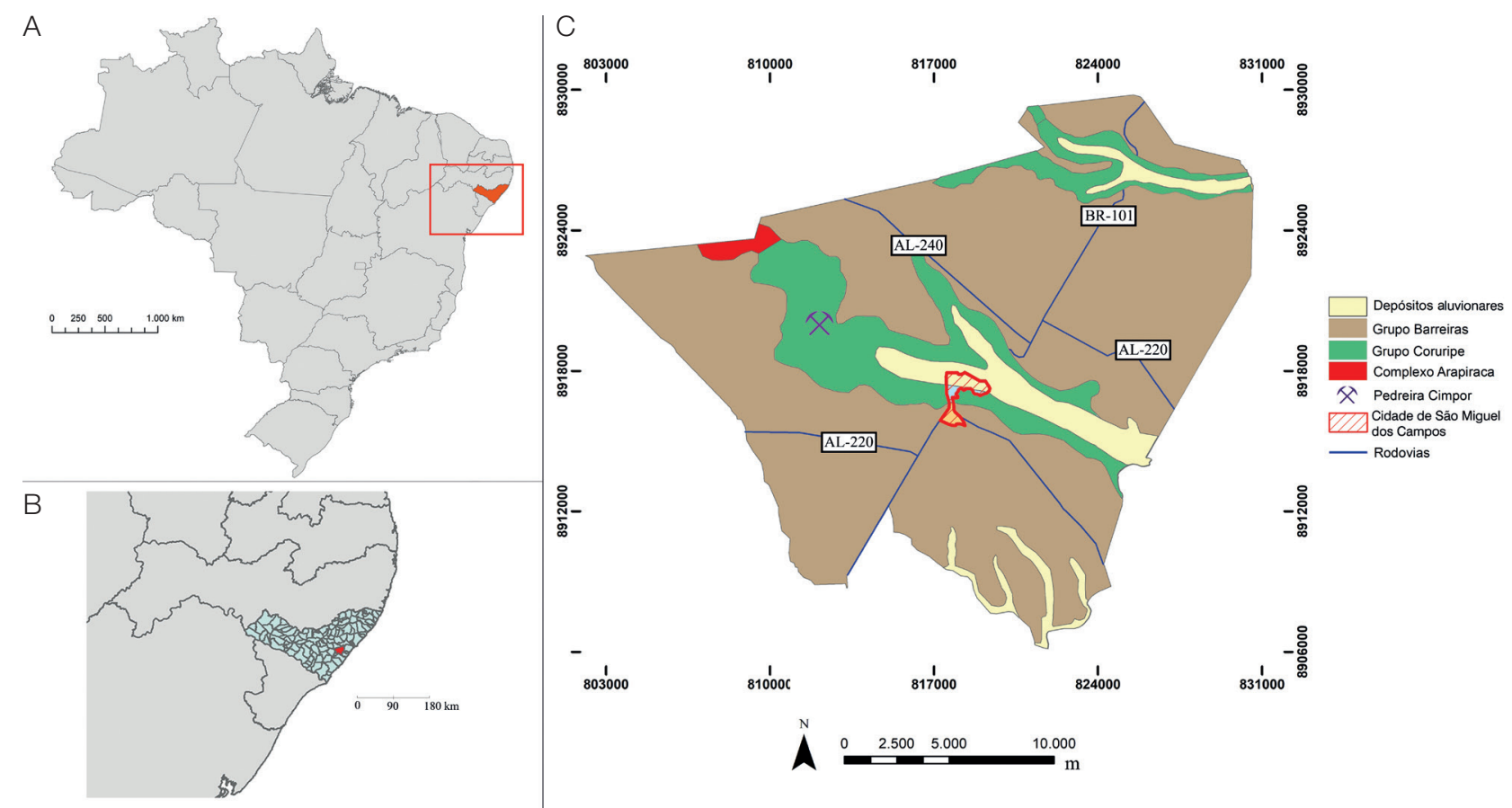

Figura 1. (A) Mapa dos estados brasileiros (em destaque o estado de Alagoas); (B) municípios do estado de Alagoas (em destaque a cidade de São Miguel dos Campos); (C) mapa geológico do município de São Miguel dos Campos (modificado de CPRM, 2009). 
os bioclastos estão dispersos na matriz, espaçados por uma distância maior que o comprimento máximo das valvas e podem ser representados por wackestones e mudstones.

\section{Grau de fragmentação}

Três classes foram propostas neste trabalho para classificar a fragmentação das conchas em coquinas: baixa (0), média (1) e alta (2) (Figura 2D), com base na análise visual da biofábrica. $\mathrm{O}$ baixo grau de fragmentação (0) corresponde a conchas bem preservadas em uma matriz micrítica ou esparítica, onde há pouco fragmento de concha e predomínio de conchas inteiras. O grau de fragmentação médio (1) corresponde a conchas parcialmente preservadas em uma matriz com menor densidade de fragmentos bioclásticos, há o predomínio de conchas inteiras em relação a fragmentadas. Por último, o alto grau de fragmentação (2) corresponde a biofábricas que apresentam conchas bem fragmentadas, onde parte da matriz é composta por fragmentos de concha e ocorrem raras valvas totalmente preservadas.

Para a classificação de abrasão/arredondamento também foi proposto três categorias (Figura 2D): valvas sem sinais de abrasão com bordas de conchas preservadas (0), valvas com pouco sinal de abrasão, cujas bordas apresentam ligeiros sinais de arredondamento e desgaste (1) e valvas bem arredondadas (2).

\section{Quantificação e classificação da porosidade}

A quantificação da porosidade foi realizada a partir das imagens de lâminas delgadas por meio do software Imago.
Esse software é capaz de isolar o espaço poroso dos sólidos resultando em uma imagem binarizada em dois tons, geralmente branco e preto, onde é possível quantificar em porcentagem o espaço poroso. A binarização pode ser realizada das seguintes maneiras: por meio de histogramas RGB, HSI ou por meio das redes neurais. Utilizou-se o método de redes neurais no processo de binarização, no qual o usuário seleciona o campo de cores que corresponde a poro e não poro. As imagens digitais foram obtidas a partir de câmera fotográfica acoplada a um microscópio petrográfico com aumento de 10 vezes. Diversos pesquisadores utilizam o método de binarização para quantificar a porosidade em rochas (Anselmetti et al., 1998; Mazurkiewicze Mlynarczuk, 2013; Rego e Bueno, 2015; Datta et al., 2016).

A classificação da porosidade segue o modelo proposto por Choquette e Pray (1970), que classifica o espaço poroso em categorias seletivas ou não seletivas quanto à fábrica.

\section{Redes neurais: Self organizing Map}

Neste trabalho, o método de redes neurais SOM (Self-Organizing Map - Mapa Auto-Organizável) foi aplicado para avaliar a relação entre as propriedades tafonômicas e a porosidade. Desenvolvido por Kohonen (2001), SOM não requer conhecimento prévio para identificação de classes. A técnica é formada por nós conectados, também chamados de neurônios, que formam uma rede, dando nome ao algoritmo (Figura 3).

O método tem como objetivo ajustar a localização dos neurônios na malha, adaptando a rede aos dados de entrada por meio da distância Euclidiana entre eles. Assim, o método aproxima os nós das amostras de entrada mais próximas e,
A

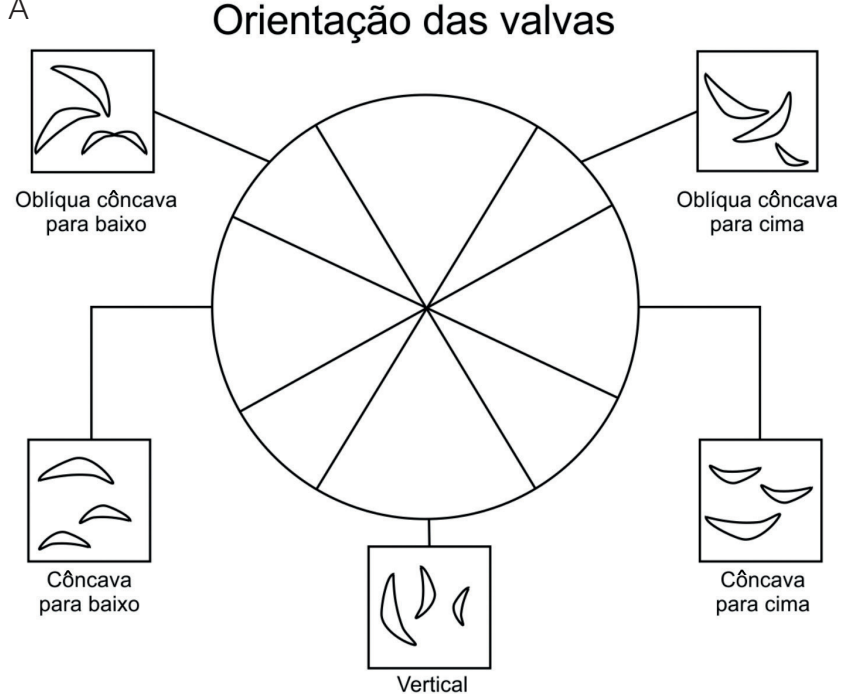

B

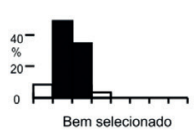

C

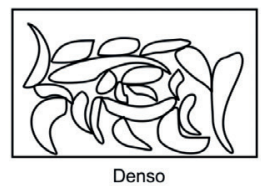

D

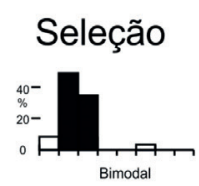

Empacotamento

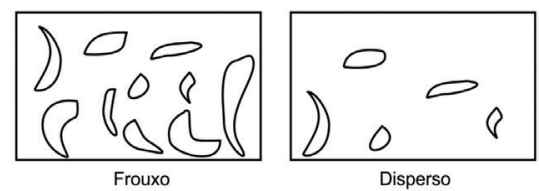

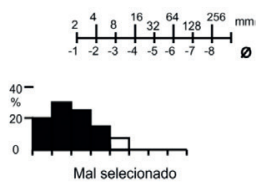

Mal selecionado

Disperso

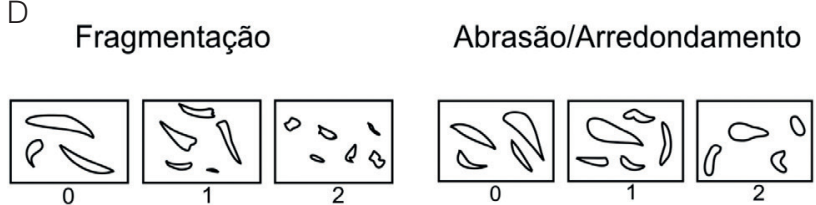

Figura 2. Características tafonômicas (adaptado de Kidwell e Holland, 1991). (A) Orientação das valvas; (B) seleção; (C) empacotamento das conchas; (D) fragmentação, abrasão e arredondamento das valvas. 
portanto, semelhantes, e os distancia das divergentes, mais distantes. Visto que o método adapta não só o neurônio mais próximo da amostra de entrada, mas também os seus vizinhos, a rede mantém a topografia do mapa.

Uma vez que a saída do algoritmo é uma malha de neurônios em duas dimensões, é possível avaliar visualmente os agrupamentos por meio do mapa de distâncias entre os neurônios, chamado de Matriz-U. Nesta matriz, as cores quentes representam maiores distâncias e estão associadas a neurônios com padrões distintos, enquanto cores frias representam neurônios próximos com padrões similares. Além disso, os mapas das projeções das variáveis de entrada auxiliam o intérprete na identificação das características dos grupos identificados pela técnica. Detalhes do funcionamento da rede neural estão presentes no trabalho de Kohonen (2001).

\section{RESULTADOS E DISCUSSÃO}

\section{Análise de fácies}

O levantamento do perfil estratigráfico está apresentado na Figura 4. As principais litologias descritas foram rudstones, grainstones e packstones, e em menor quantidade, wackestones e mudstones. As litologias carbonáticas são compostas principalmente por bioclastos de bivalves e variam quanto ao grau de preservação e orientação das valvas, apresentando normalmente granulometrias entre 2 e $6 \mathrm{~mm}$. Camadas com valvas bem fragmentadas cuja granulometria é inferior a $2 \mathrm{~mm}$ também ocorrem.

As coquinas do tipo rudstone são compostas de bioclastos de bivalves com granulometria entre 4 e $6 \mathrm{~mm}$, apresentam grau de fragmentação intermediário e grau de empacotamento denso. $\mathrm{O}$ arranjo das conchas varia de concordante a aleatório e são predominantemente desarticuladas, apresentando sinais de abrasão e arredondamento. Alguns rudstones podem apresentar grãos de quartzo na matriz e arranjo caótico das conchas, com padrões de empilhamento e aninhamento.

De maneira geral, essas camadas podem variar de $0,3-3 \mathrm{~m}$ de espessura, possuem geometria tabular e extensão lateral com mais de dezenas de metros ( $>100 \mathrm{~m})$. Camadas que apresentam arranjo caótico dos bioclastos tendem a apresentar contato com base erosiva (Figuras 5A e 5B).

Os packstones/floatstones são compostos por bioclastos preservados e fragmentos de conchas, a granulometria de valvas bem preservadas varia de 2 a $4 \mathrm{~mm}$, enquanto os
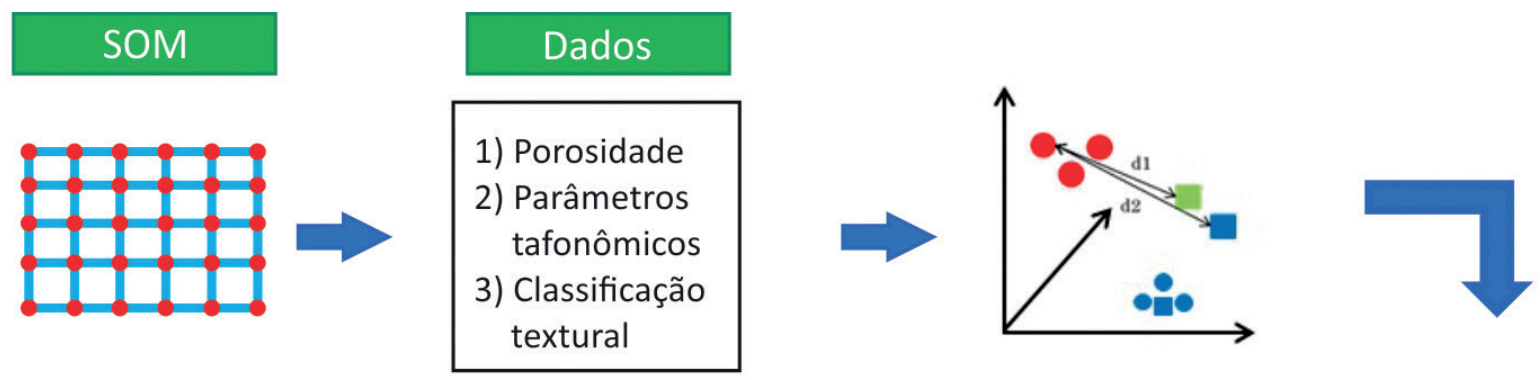

\section{Mapas de distribuição das variáveis de entrada}

\section{Agrupamentos}
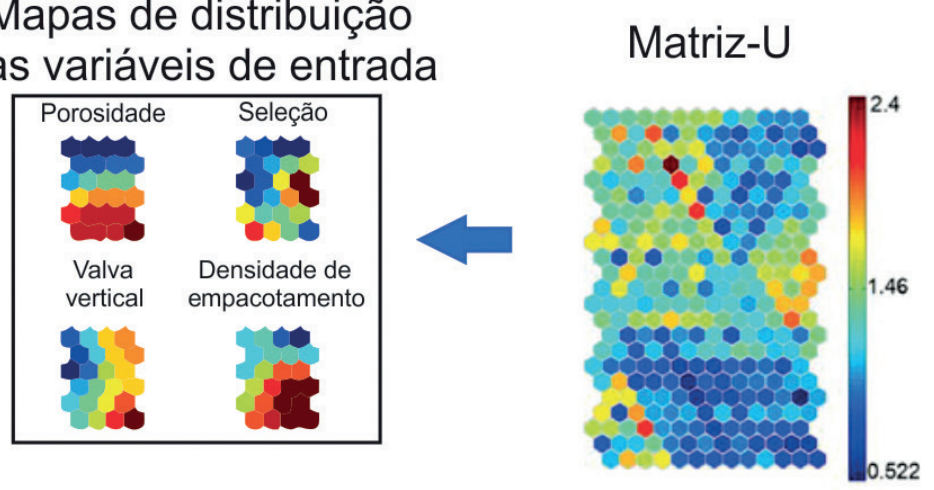

Mapa 2D

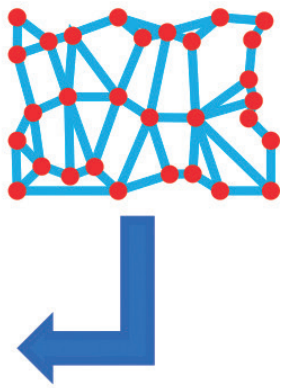

Figura 3. Fluxograma do algoritmo Self-Organization Map treinado com dados de porosidade e parâmetros tafonômicos. O método calcula as distâncias Euclidianas entre os nós da rede e as amostras de entrada e rearranja a localização dos nós, aproximando os neurônios da amostra mais próxima. A distância entre os neurônios é visualizada por meio da Matriz-U que guia o intérprete na identificação de grupos. Além dessa matriz, os mapas de distribuição das variáveis de entrada auxiliam a caracterização de cada um dos grupos e os limites entre eles. 
fragmentos possuem valores inferiores a $1 \mathrm{~mm}$, apresentam grau de fragmentação intermediário e o grau de empacotamento varia de denso a frouxo. $\mathrm{O}$ arranjo das conchas varia de concordante a aleatório, são predominantemente desarticuladas, embora ocorram raros casos de valvas fechadas. Sinais de abrasão também são observados em algumas valvas. A matriz dessas rochas pode conter argila, silte, grãos de quartzo e pequenos fragmentos de conchas. Em alguns packstones, é possível encontrar conchas aninhadas e empilhadas.

Essas camadas variam de $0,3-1 \mathrm{~m}$ de espessura e possuem geometria tabular ou em forma de cunha (Figuras $5 \mathrm{~A}$ e 5C), com extensão lateral de mais de $100 \mathrm{~m}$. Assim como nos rudstones, biofábricas com arranjo caótico das conchas apresentam contato erosivo na base.
Coquinas do tipo wackestone/floatstone são compostas de bivalves com granulometria média de $2 \mathrm{~mm}$, porém, em alguns casos, as valvas podem alcançar $6 \mathrm{~mm}$, as conchas apresentam grau de fragmentação intermediário a baixo e grau de empacotamento disperso. $\mathrm{O}$ arranjo das conchas é caótico, pode haver ocorrências de valvas articuladas e intermediário a baixo grau de abrasão e arredondamento. A matriz apresenta grãos de quartzo, pequenos fragmentos de conchas e predomínio de argilas (Figuras 5D e 5E).

As camadas apresentam espessura máxima de $0,3 \mathrm{~m}$, geralmente intercaladas com mudstones, apresentam forma de cunha e extensão lateral inferior às litologias anteriores. Na base dessa litologia, é comum encontrar superfícies erosivas.
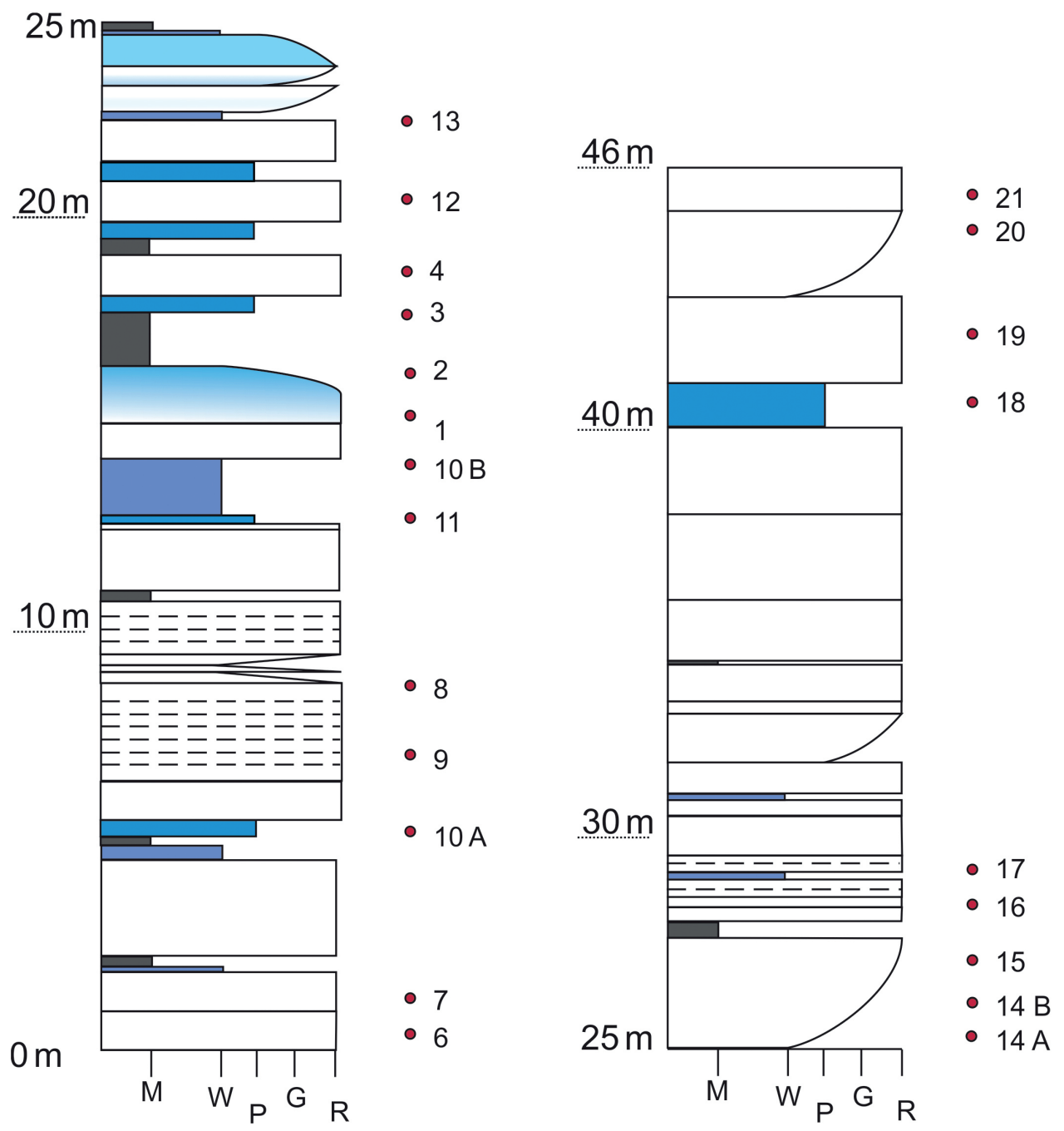

Figura 4. Seção estratigráfica esquemática da distribuição de fácies carbonáticas da Formação Morro do Chaves. As litologias são compostas principalmente por bioclastos de bivalves. 
Os mudstones podem ou não apresentar bioclastos. De maneira geral, os bioclastos são pequenos, menores que $2 \mathrm{~mm}$, com pouca ocorrência de valvas fragmentadas, sem sinais de abrasão, e podem conter valvas de bivalves fechadas
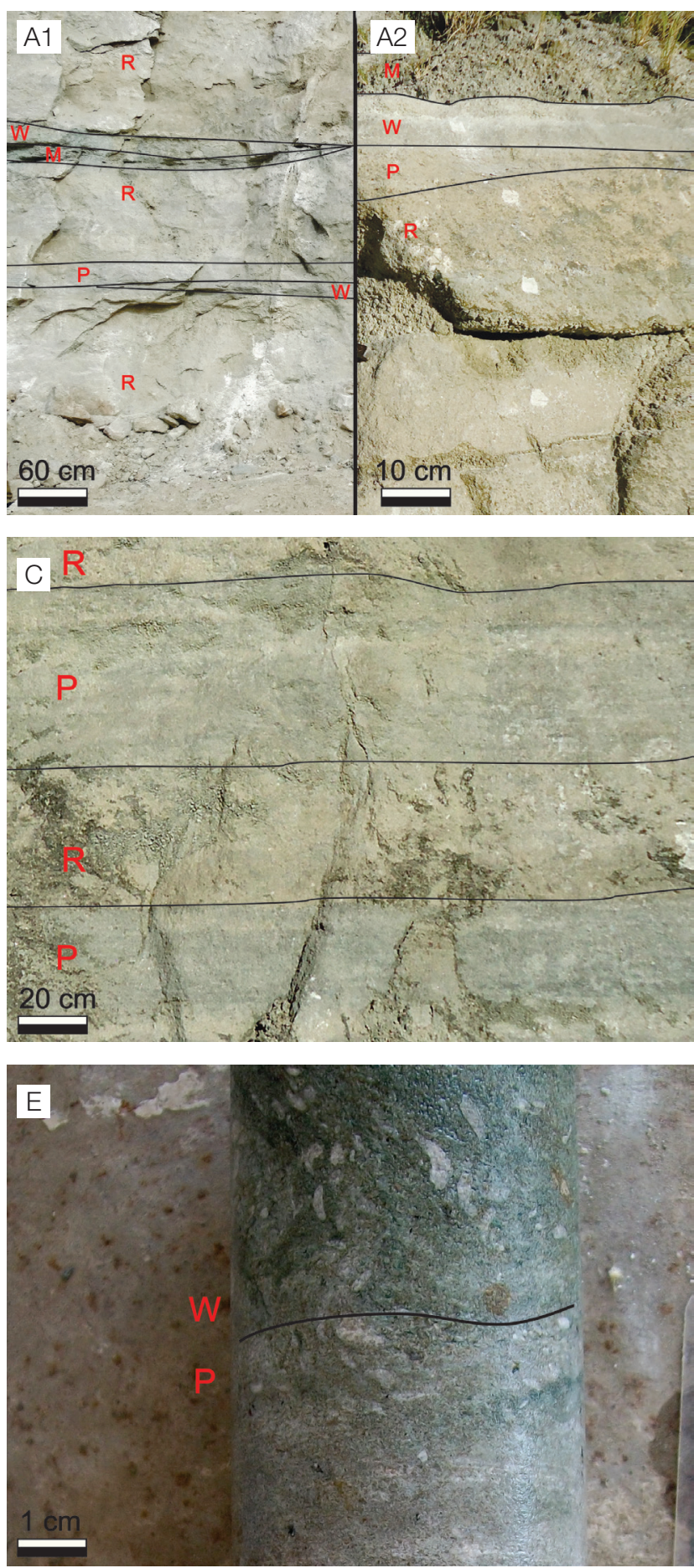

R: rudstones; W: wackestones; M: mudstones; P: packstones.

Figura 5. (A1-2) Seção aflorante dos principais litotipos, geometria das camadas e contatos; (B) contato erosivo entre packstone e rudstone; (C) contato plano paralelo entre packstone (abaixo) e rudstone (acima); (D-E) testemunho de sondagem exibindo wackestones com disposição caótica das conchas; (F) mudstone laminado com gretas de dessecação (mud-cracks). ou abertas em formato borboleta. De maneira geral, são camadas tabulares com espessuras que variam entre $0,1-1 \mathrm{~m}$ e podem apresentar ou não superfícies erosivas no topo ou estruturas de dessecação tipo mud-cracks (Figura 5F).
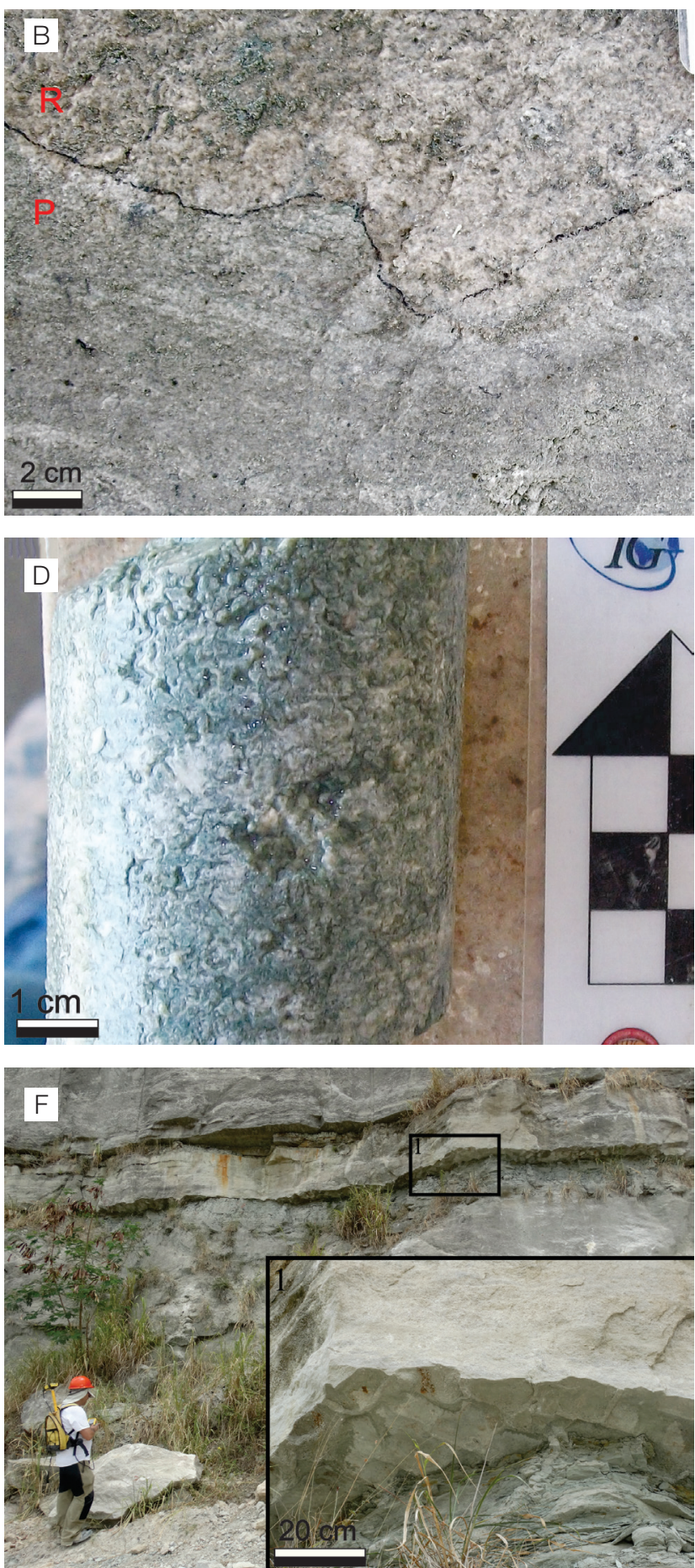


\section{Redes neurais e biofábrica}

No total, foram analisadas 20 amostras de coquinas, compreendendo rudstones, grainstones, packstones e wackestones. Em todas as amostras, nove variáveis foram obtidas:

1. porosidade;

2. seleção;

3. orientação das conchas em relação ao acamamento valva concordante;

4. valva oblíqua;

5. valva vertical;

6. grau de empacotamento das conchas;

7. grau de fragmentação;

8. abrasão/arredondamento;

9. granulometria média das valvas.

A Tabela 1 apresenta os dados levantados para cada amostra coletada.

O método SOM identificou oito padrões no conjunto de dados amostrais que definiram os grupos apresentados na Figura 6. O resultado dos agrupamentos está representado por meio do mapa particionado (Figura 6A), realizado a partir da análise visual da Matriz-U, e interpretados com auxílio dos mapas de influência de cada uma das variáveis que definiram a intensidade de valor para cada grupo (Figura 6B).
Segundo análise da classificação assistida realizada com SOM, observa-se que os grupos de maior porosidade são os de número 1, 2 e 5, denominados de Agrupamento 1 (A1); os de porosidade intermediária são representados pelos grupos de número 4 e 6 , denominados de Agrupamento 2 (A2); e os de baixa porosidade são os grupos de número 3,7 e 8 , denominados de Agrupamento 3 (A3).

Com base na Figura 6, as variáveis que possuem maior correlação com a porosidade são: densidade de empacotamento, grau de fragmentação, grau de abrasão e granulometria média das valvas. Por outro lado, a seleção e a orientação das valvas com relação ao acamamento não apresentaram correlação com a porosidade.

A Tabela 2 a seguir resume as principais características dos grupos de $1 \mathrm{a} 8$ com relação à porosidade e às características tafonômicas.

\section{Agrupamento 1: amostras com alta porosidade}

Os grupos de maior porosidade apresentam como principais características tafonômicas: grau de empacotamento denso, alto a intermediário grau de fragmentação, alto a intermediário grau de arredondamento e alta granulometria, com conchas superiores a $4 \mathrm{~mm}$.

Os principais litotipos que compõe esse agrupamento são coquinas do tipo rudstones. As amostras contidas em

Tabela 1. Dados de porosidade e parâmetros tafonômicos das amostras coletadas.

\begin{tabular}{|c|c|c|c|c|c|c|c|c|c|c|}
\hline Amostra & $\begin{array}{c}\text { Porosidade } \\
(\%)\end{array}$ & Seleção & $\begin{array}{l}\text { V.C. } \\
(\%)\end{array}$ & $\begin{array}{l}\text { V.O. } \\
(\%)\end{array}$ & $\begin{array}{l}\text { V.V. } \\
(\%)\end{array}$ & Densidade & Fragmentação & Abrasão & Granulometria & $\begin{array}{l}\text { Grupo } \\
\text { SOM }\end{array}$ \\
\hline Coq 6 & 11,6 & 2 & 35,5 & 47,4 & 17,1 & 1 & 1 & 3 & 5 & 1 \\
\hline Coq 7 & 18 & 2 & 42,0 & 43,2 & 14,8 & 1 & 1 & 2 & 4 & 1 \\
\hline Coq 4 & 23,5 & 0 & 35,3 & 45,1 & 19,6 & 1 & 1 & 1 & 4 & 1 \\
\hline Coq 19 & 15,8 & 2 & 42,1 & 30,3 & 27,6 & 1 & 1 & 2 & 6 & 2 \\
\hline Coq 14 a & 15,9 & 0 & 30,3 & 45,5 & 24,2 & 1 & 2 & 1 & 5 & 2 \\
\hline Coq 14 b & 22,1 & 0 & 24,6 & 45,6 & 29,8 & 1 & 2 & 1 & 5 & 2 \\
\hline Coq 12 & 2 & 1 & 27,0 & 47,6 & 25,4 & 0 & 1 & 0 & 3 & 3 \\
\hline A 2 & 3 & 0 & 27,6 & 53,3 & 19,0 & 0 & 1 & 0 & 3 & 3 \\
\hline A 3 & 3,4 & 0 & 12,6 & 65,5 & 21,8 & 0 & 1 & 1 & 3 & 3 \\
\hline Coq 17 & 6,6 & 0 & 51,1 & 38,3 & 10,6 & 0 & 1 & 1 & 4 & 4 \\
\hline Coq 9 & 7,6 & 0 & 52,9 & 36,8 & 10,3 & 1 & 1 & 2 & 3 & 4 \\
\hline Coq 8 & 14,3 & 0 & 45,1 & 35,2 & 19,7 & 1 & 1 & 0 & 4 & 5 \\
\hline Coq 13 & 17 & 2 & 47,6 & 31,7 & 20,7 & 0 & 1 & 1 & 4 & 5 \\
\hline Coq 15 & 18,6 & 0 & 44,2 & 38,5 & 17,3 & 1 & 1 & 2 & 4 & 5 \\
\hline Coq 11 & 6,2 & 2 & 31,6 & 44,3 & 24,1 & 1 & 1 & 1 & 4 & 6 \\
\hline Coq $10 \mathrm{~b}$ & 11,1 & 2 & 35,7 & 45,5 & 18,8 & 1 & 1 & 1 & 4 & 6 \\
\hline Coq 10 a & 12,2 & 2 & 37,8 & 42,9 & 19,4 & 1 & 1 & 1 & 4 & 6 \\
\hline Coq 1 & 16,5 & 2 & 32,0 & 48,0 & 20,0 & 1 & 1 & 1 & 4 & 6 \\
\hline Coq 16 & 3,5 & 2 & 45,3 & 47,7 & 7,0 & 0 & 1 & 2 & 3 & 7 \\
\hline Coq 2 & 2 & 0 & 35,8 & 41,5 & 22,6 & 1 & 0 & 0 & 2 & 8 \\
\hline
\end{tabular}

V.C.: valva concordante; V.O.: valva oblíqua; V.V.: valva vertical. 
A

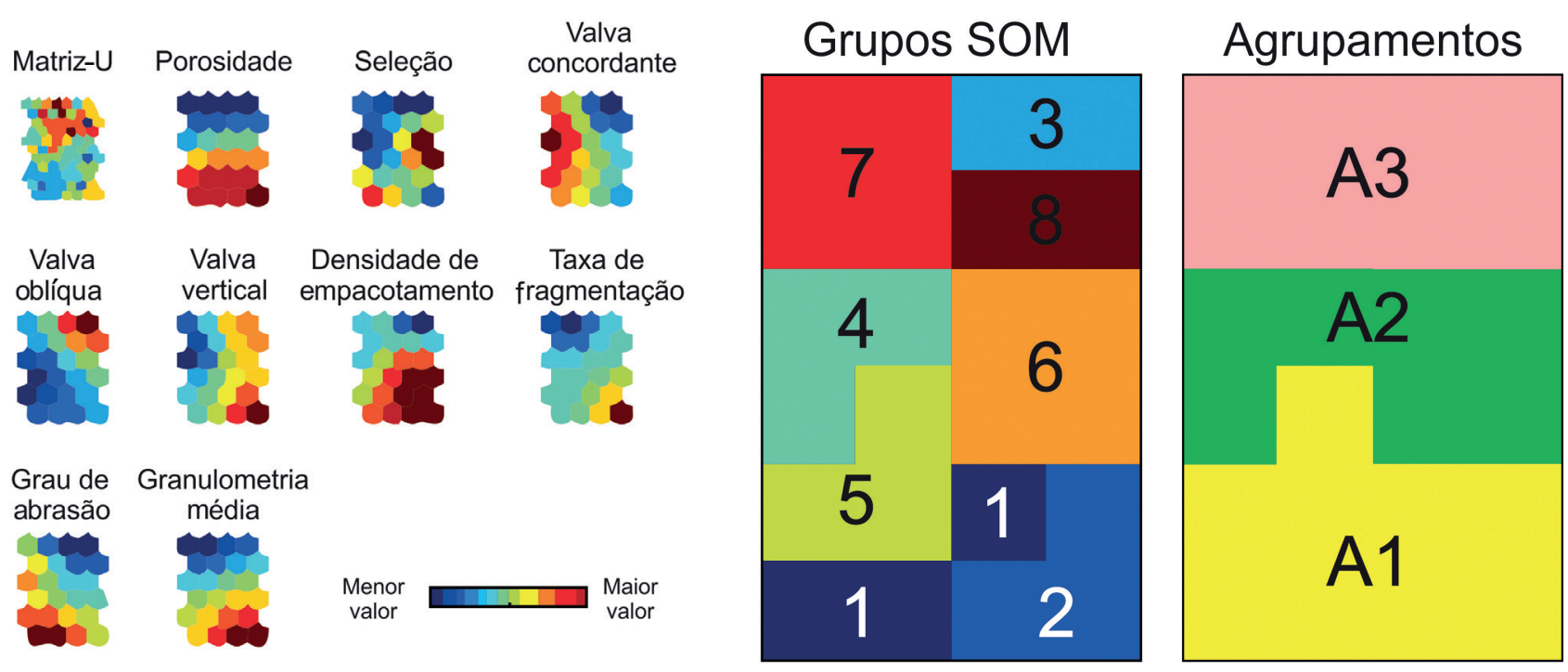

Figura 6. (A) A Matriz-U está representada no canto superior esquerdo, mostrando as distâncias entre os neurônios que deram origem ao agrupamento de (B), e os mapas de cada variável utilizada para o treinamento da rede neural. Por meio dos valores dos mapas de (A), é possível inferir as características de cada grupo definido em (B); (B) resultado do Self-Organization Map, que encontrou oito padrões distintos representados na malha da Matriz-U, e agrupamentos A1 - A3.

Tabela 2. Resumo das principais características tafonômicas e porosidade.

\begin{tabular}{ccccc}
\hline \multicolumn{5}{c}{ Mediana } \\
\hline $\begin{array}{c}\text { Grupos } \\
\text { SOM }\end{array}$ & $\begin{array}{c}\text { Porosidade } \\
\text { (\%) }\end{array}$ & $\begin{array}{l}\text { V.C. } \\
\text { (\%) }\end{array}$ & $\begin{array}{c}\text { V.O. } \\
\mathbf{( \% )}\end{array}$ & $\begin{array}{c}\text { V.V. } \\
\mathbf{( \% )}\end{array}$ \\
\hline 1 & 18,0 & 35,5 & 45,1 & 17,1 \\
2 & 15,9 & 30,3 & 45,5 & 27,6 \\
3 & 3,0 & 27,0 & 53,3 & 21,8 \\
4 & 7,1 & 52,0 & 37,5 & 10,5 \\
5 & 17,0 & 45,1 & 35,2 & 19,7 \\
6 & 11,7 & 33,9 & 44,9 & 19,7 \\
7 & 3,5 & 45,3 & 47,7 & 7,0 \\
8 & 2,0 & 35,8 & 41,5 & 22,6 \\
\hline \multicolumn{5}{c}{ Classes majoritárias de cada grupo } \\
\hline
\end{tabular}

Seleção Densidade Fragmentação Abrasão Granulometria

\begin{tabular}{lllll}
\hline 2 & 1 & 1 & 2 & 4 \\
0 & 1 & 2 & 1 & 5 \\
0 & 0 & 1 & 0 & 3 \\
0 & 0 & 1 & 1 & 3 \\
0 & 1 & 1 & 1 & 4 \\
2 & 1 & 1 & 1 & 4 \\
2 & 0 & 1 & 2 & 3 \\
0 & 1 & 0 & 0 & 2 \\
\hline
\end{tabular}

V.C.: valva concordante; V.O.: valva oblíqua; V.V.: valva vertical.
A1 apresentam valvas de bivalves com granulometrias superiores a $4 \mathrm{~mm}$, que podem ser encontradas dispostas de forma caótica - representada pelo grupo 2 - ou concordante com o acamamento - como representado pelo grupo 1. De maneira geral, apresentam uma matriz composta de fragmentos de conchas e grãos de quartzo e ocorrência de cimento espático. Os bioclastos encontram-se neomorfisados com preservação da estrutura aragonítica original da concha (Figura 7A). Em algumas amostras, há ocorrência de alto grau de dissolução das valvas, cimento e matriz, onde é quase imperceptível identificar os limites entre valvas e cimento.

A porosidade é predominantemente do tipo interpartícula, intrapartícula, móldica e vugular (Figuras 7A e 7B); em menor quantidade, observa-se porosidade por canal e por fratura, e variam de 11 a $23 \%$. As porosidades encontram-se conectadas onde é comum a interação dos poros primários com os secundários.

\section{Agrupamento 2: amostras com porosidade intermediária}

As principais características tafonômicas de A2 são grau de empacotamento frouxo a denso, grau intermediário de fragmentação, grau intermediário de arredondamento e granulometria entre $3-4 \mathrm{~mm}$.

O principal grupo de amostras que compõe A2 são rudstones e packstones. Assim como no grupo $\mathrm{A} 1$, as amostras 

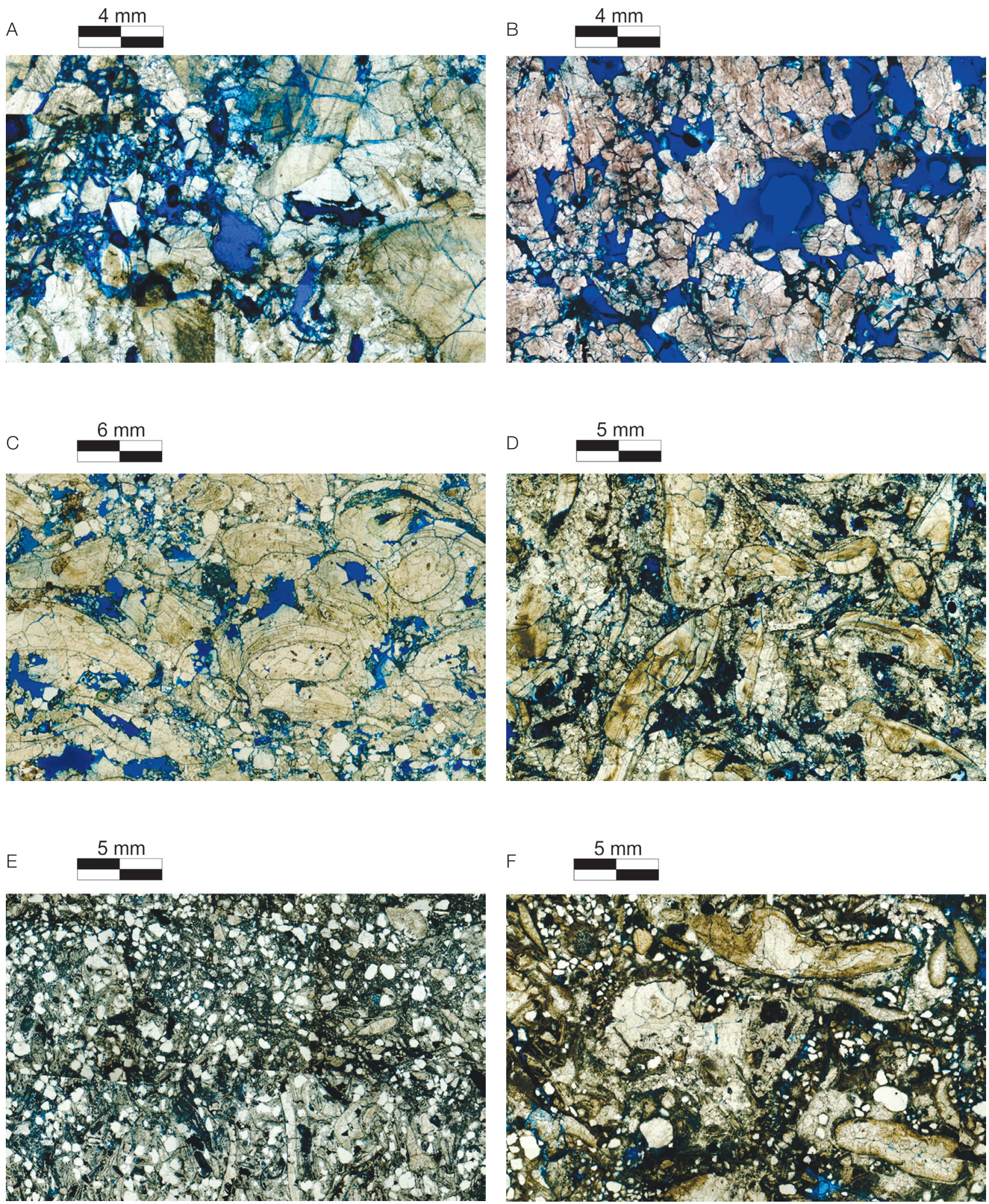

Figura 7. Lâminas delgadas dos agrupamentos A1 - A3. (A-B) Amostras de A1 com ênfase nos poros móldicos, interpartícula e vugulares; (C-D) amostras de A2 com ênfase nos poros interpartícula e ocorrência de cimento e finos que obstruem os poros; (E-F) amostras de A3 com pouca porosidade e alta concentração de finos e cimento obstruindo os poros (cristais de pirita também estão presentes). 
contidas em A2 apresentam valvas de bivalves dispostas de forma caótica ou concordante com o acamamento com granulometrias entre $2-4 \mathrm{~mm}$, variando de bem selecionada a bimodal, ocorrendo valvas de maior tamanho (Figuras 7C e 7D). De maneira geral, A2 apresenta uma matriz composta por fragmentos de conchas, grãos de quartzo, material fino micrítico recristalizado em forma de cimento e ocorrência de cimento espático que obstrui grande parte da porosidade. Assim como A1, os bioclastos encontram-se neomorfisados. A porosidade nessas amostras é predominantemente do tipo interpartícula, intrapartícula (Figuras 7C e 7D) e, em menor quantidade, móldica.

As porosidades desse grupo de amostras variam de 7 a $15 \%$ e encontram-se interconectadas; poucas amostras possuem poros isolados sem conectividade.

\section{Agrupamento 3: amostras de baixa porosidade}

A3 apresenta as seguintes características tafonômicas: baixo grau de empacotamento das conchas, baixo grau de fragmentação, baixo grau de arredondamento e baixa granulometria.

As principais amostras desse agrupamento são packstones e wackestones. A3 apresenta valvas de bivalves dispostas de forma caótica ou concordante com o acamamento com granulometrias que variam entre $2-3 \mathrm{~mm}$. A matriz dessas rochas é composta principalmente por fragmentos de conchas, grãos de quartzo e alta quantidade de material fino micrítico, com ocorrência de cimento espático de calcita mosaico em drusa (Figuras 7E e 7F).

Assim como A1 e A2, os bioclastos encontram-se neomorfisados. As porosidades nessas amostras são predominantemente do tipo interpartícula, intrapartícula e, em raras ocorrências, móldica. As porosidades desse grupo de amostras variam de 0 a $7 \%$, normalmente são conectadas por dutos de dissolução ou fraturas.

\section{Relação entre biofábrica, ambiente deposicional e porosidade}

Acumulações conchíferas podem ocorrer em diversos ambientes deposicionais, como rios, lagos, mares e oceanos, e com base nas condições de preservação e acumulação das valvas é possível interpretar as características energéticas de cada depósito. Como apresentado por alguns autores (Fürsich e Oschmann, 1986, 1993; Kidwell, 1986, 1991; Kidwell e Holland, 1991), acumulações conchíferas geradas em ambientes de alta energia tentem a apresentar valvas fragmentadas, desarticuladas, com sinais de abrasão e ausência de material fino, como micrita na matriz. Exemplos em lagos recentes apontam que o retrabalhamento das conchas está vinculado diretamente à lâmina d'água, ou seja, apresentam maior grau de fraturamento nas porções rasas cujo ambiente é de maior energia (McGlue et al., 2010; Hassan et al., 2014). Além disso, a ausência de valvas fechadas e a ocorrência de conchas com sinas de abrasão são um indício de que essas conchas foram retrabalhadas (Tietze e Francesco, 2014). Já nos ambientes de menor energia, os bioclastos se encontram mais preservados, articulados, podendo ser encontrados até mesmo em condições de vida nas quais muitas vezes ocorre matriz argilosa.

Com base nessas características, podemos concluir que as coquinas do tipo grainstone e rudstone são produtos de um ambiente de maior energia comparadas às coquinas do tipo packstone e wackestone. Os depósitos de ambiente de alta energia na Formação Morro do Chaves apresentam o retrabalhamento por correntes de fundo e/ou ondas durante períodos de tempo bom ou eventos de tempestade que removem o material fino, resultando em acumulações conchíferas com valvas bem fragmentadas, selecionadas e com sinais de abrasão (Tavares et al., 2015; Chinelatto et al., 2018). Algumas amostras do A1 e do A2 apresentam características de coquinas formadas em ambiente de tempestade proximal, cujas principais características são o empacotamento denso, a disposição caótica, aninhada ou empilhada das conchas, com grau médio de fragmentação e raras ocorrências de valvas articuladas, além de apresentar contatos erosivos na base (Tavares et al., 2015; Chinelatto et al., 2018). As coquinas do A3 são as de menor energia, localizadas abaixo do nível de onda de tempo bom e são interpretadas como acumulações de eventos de tempestade de baixa energia (Tavares et al., 2015; Chinelatto et al., 2018).

Por meio da análise das características tafonômicas de cada agrupamento, podemos observar que o grupo de coquinas com alta porosidade são aqueles interpretados como sendo produtos de ambientes de maior energia, como apresentado pelo A1 e pelo A2, enquanto as rochas do A3, que apresentam características de ambientes de baixa energia, apresentam os menores valores de porosidade.

A porosidade primária interpartícula de $\mathrm{A} 1$ e $\mathrm{A} 2$ pode ser resultado do retrabalhamento, do transporte das valvas e do joeiramento do material mais fino que pode ser ocasionado por ondas, correntes ou eventos periódicos de tempestade. Esse tipo de porosidade é controlado pelo tamanho da partícula, pela seleção e pelo volume de cimento (Lucia, 2007). A3, no entanto, é o grupo que apresenta menor valor de porosidade primária, os poros estão praticamente preenchidos por micrita e pseudoesparita. Nesse caso, a porosidade desse grupo se resume a poros móldicos, por fratura ou pequenos canais de dissolução.

A porosidade secundária é comum em todos os agrupamentos e são predominantemente dos tipos móldica e vugular. A porosidade móldica é controlada pela granulometria das conchas, pois quanto maior o bioclasto maior será o molde gerado. No caso de A1 e A2, há o predomínio de empacotamentos densos de alta granulometria que, associados com alta taxa de dissolução, resultam em alta 
quantidade de poros móldicos e vugs. Além disso, os poros primários podem facilitar a percolação de água não saturada em calcita, resultando na criação de vugs. No caso de A3, a quantidade de conchas é menor, além de sua granulometria ser inferior, se comparada a dos outros grupos, o que resulta em uma rocha com menor quantidade de poros móldicos e vugulares. Devido à ausência de poros primários em $\mathrm{A} 3$, a dissolução e a criação de vugs são menores comparadas a A1 e A2.

Analisando A1 e A2, nota-se que a intensidade da cimentação e a presença de material fino variam. Grande parte da porosidade primária encontra-se obstruída por microesparita e pequenas quantidades de micrita, resultado da mudança da energia deposicional do ambiente e pela precipitação de cimento.

As porosidades por dissolução (intrapartícula, móldica e vugs) são formadas durante as diferentes fases diagenéticas. Durante a eodiagenese temos o neomorfismo das conchas, no qual temos a substituição dos cristais originais de aragonita por calcita de forma que esse preenchimento possa ocorrer de forma incompleta preservando porosidades do tipo intrapartícula. Os exemplos do A1 (Figuras 7A e 7B) e do A2 (Figuras 7C e 7D) apresentam dissolução de conchas inteiras e de seus fragmentos como também do cimento intergranular, resultando em uma porosidade secundária. A cimentação inicial por calcita no espaço poroso primário sustenta o arcabouço da rocha, limitando a redução dos poros por compactação, no entanto a cimentação diminui o volume do poro.

Em A1, a porosidade por dissolução tem maior destaque comparado aos outros grupos, o alto grau de fragmentação das conchas combinado com um fluido capaz de dissolver os bioclastos são uma combinação importante para favorecer a formação de porosidade secundária (quanto mais fragmentadas as conchas, mais fácil será a dissolução). No A2, a diagênese pode contribuir ou obliterar a porosidade. Nas amostras com menor porosidade (valor próximo a 7\%), a cimentação obstrui grande parte do sistema poroso inicial e ocorre pouca dissolução tanto das conchas como do cimento, enquanto nas amostras de maior porosidade (valor superior a 14\%) a cimentação é baixa, preservando porosidades primárias, nas quais a dissolução é capaz de remover pequenos grãos e cimento gerando vugs ou porosidades parcialmente móldicas.

A3 é o grupo de menor porosidade. Como dito anteriormente, grande parte da porosidade está obstruída por material fino e cimento. Durante a diagênese, o pouco espaço poroso pode ser completamente obstruído por cimento de calcita e a micrita chega a se recristalizar formando cimento microesparitíco. As conchas não sofrem processo de dissolução e a pouca porosidade móldica é rara e ocorre parcialmente em bioclastos ou pequenos fragmentos de conchas. Nesse grupo, a porosidade pode ser controlada pela ocorrência de pequenas fraturas que podem ser alargadas pela dissolução.

\section{CONCLUSÃO}

Analisando as características da biofábrica (porosidade, seleção, orientação das conchas, grau de empacotamento, grau de fragmentação, abrasão/arredondamento e granulometria média das valvas) e diagenéticas das coquinas da Formação Morro do Chaves, podemos concluir que há uma diferença entre o valor da porosidade de coquinas formadas em ambientes de alta e baixa energia.

As coquinas depositadas em ambientes de alta energia apresentam os maiores valores de porosidade, pois a ação de ondas e/ou correntes favorecem a preservação da porosidade interpartícula, pois promove o joeiramento de material fino. Essas coquinas vão apresentar uma biofábrica com conchas bem fragmentadas, orientadas ou não, com sinais de arredondamento e desarticuladas.

Coquinas depositadas em ambientes de baixa energia (por exemplo, fundo de lago) possuem maior quantidade de material fino entre os bioclastos, obstruindo a porosidade primária e resultando em rochas com pouca ou nenhuma porosidade. Normalmente, a biofábrica apresentará bioclastos mais preservados, com poucos fragmentos, orientados ou não, e frequentes conchas articuladas.

Coquinas produtos de evento de tempestade, como observado em alguns casos de A1 e A2, podem apresentar condições favoráveis à preservação de porosidade, pois mesmo tempestades podem joeirar o material fino e depositar extensas camadas de coquinas em regiões onde normalmente prevalecem condições de baixa energia, abaixo do nível de ondas de tempo bom.

A diagênese também revela uma boa relação com a porosidade e com as características da biofábrica, principalmente com as coquinas que apresentam alto grau de fragmentação. Quando essas rochas são submetidas à dissolução, esses fragmentos são facilmente removidos, formando diversos poros móldicos e vugulares.

\section{AGRADECIMENTOS}

Agradecemos ao Prof. Dr. Celso Peres Fernandes, a disponibilidade do software Imago; ao Departamento de Geologia e Laboratório de Laminação da Universidade Estadual de Campinas (Unicamp); ao financiamento promovido pelo Conselho Nacional de Desenvolvimento Científico e Tecnológico (CNPq) (Projeto n ${ }^{\circ}$ 132487/20144) e pela Coordenação de Aperfeiçoamento de Pessoal de Nível Superior (Capes) (Projeto $\mathrm{n}^{\circ}$ 1579147); aos amigos Mateus Basso e Aline Maria Poças Belila, que acompanharam as atividades de campo; e aos revisores anônimos as dicas e observações sugeridas. A todos, um forte abraço. 


\section{REFERÊNCIAS}

Abrahão, D., Warme, J. E. (1990). Lacustrine and associated deposits in a rifted continental margin-Lower Cretaceous Lagoa Feia Formation, Campos Basin, off shore Brazil. In: B. J. Katz (Ed.), Lacustrine Basin Exploration - Case Studies and Modern Analogs (v. 50, 287-305). American Association of Petroleum Geologists Memoir.

Anselmetti, F. S., Luthi, S., Eberli, G. P. (1998). Quantitative Characterization of Carbonate Pore Systems by Digital Image Analysis. AAPG Bulletin, 82(10), 1815-1836.

Aquino, G. S., Lana, M. C. (1990). Exploração na Bacia de Sergipe-Alagoas: O "Estado da Arte”. Boletim de Geociências da Petrobras, 4(1), 75-84.

Baumgarten, C. S., Dultra, A. J. C., Scuta, M. S., Figueiredo, M. V. L., Sequeira, M. F. P. B. (1988). Coquinas da Formação Lagoa Feia, Bacia de Campos: evolução da Geologia de Desenvolvimento. Boletim de Geociências da Petrobras, 2, 27-36.

Belila, A. M. P. (2014). Caracterização petrofísica dos carbonatos da Formação Morro do Chaves, Bacia de Sergipe-Alagoas. Dissertação (Mestrado). Campinas: Instituto de Geociências - Universidade Estadual de Campinas.

Burchette, T. P. (2012). Carbonate rocks and petroleum reservoirs: A geological perspective from the industry. Geological Society, London, Special Publications, 370(1), 17. http://dx.doi.org/10.1144/SP370.14

Bust, V. K., Oletu, J. U., Worthington, P. F. (2011). The challenges for carbonate petrophysics in petroleum resource estimation. SPE Reservoir Evaluation \& Engineering, 14(1), 25-34. https://doi.org/10.2118/142819-PA

Campos Neto, O. P. A. C., Lima, W. S., Cruz, F. E. G. (2007). Bacia de Sergipe-Alagoas. Boletim de Geociências da Petrobras, 15(2), 405-415.

Carvalho, M. D., Praça, U. M., Silva-Telles Jr., A. C., Jahnert, R. J., Dias, J. L. (2000). Bioclastic carbonate lacustrine facies models in the Campos Basin (Lower Cretaceous), Brazil. In: E. H. Gierlowski-Kordesch, K. R. Kelts (Eds.), Lake Basins Through Space and Time: AAPG Studies in Geology (46, 245-256). Tulsa, Oklahoma: AAPG..

Chang, H. K., Assine, M. L., Corrêa, F. S., Tinen, J. S., Vidal, A. C., Koike, L. (2008). Sistemas petrolíferos e modelos de acumulação de hidrocarbonetos na Bacia de Santos. Revista Brasileira de Geociências, 38(2 Supl. 1), 29-46.
Chinelatto, G. F., Vidal, A. C., Kuroda, M. C., Basilici, G. (2018). A taphofacies model for coquina sedimentation in lakes (Lower Cretaceous, Morro do Chaves Formation, NE Brazil). Cretaceous Research, 85, 1-19. https://doi. org/10.1016/j.cretres.2017.12.005

Choquette, P. W., Pray, L. C. (1970). Geologic nomenclature and classification of porosity in sedimentary carbonates. The American Association of Petroleum Geologists Bulletin, 54(2), 207-250.

Corbett, P. W. M., Estrella, R., Rodriguez, A. M., Shoeir, A., Borghi, L., Tavares, A. C. (2016). Integration of Cretaceous Morro do Chaves rock properties (NE Brazil) with the Holocene Hamelin Coquina architecture (Shark Bay, Western Australia) to model effective permeability. Petroleum Geoscience, 22(2), 105-122. https://doi.org/10.1144/ petgeo2015-054

Datta, D., Thakur, N., Ghosh, S., Poddar, R., Sengupta, S. (2016). Determination of porosity of rocks samples from photomicrographs using image analysis. IEEE 6th International Conference on Advanced Computing.

Dunham, R. J. (1962). Classification of carbonate rocks according to depositional texture. In: W. E. Ham (Ed.), Classification of carbonate rocks: American Association of Petroleum Geologists Memoir (v. 1, 108-121). Tulsa, Oklahoma: AAPG.

Ehrenberg, S. N., Nadeau, P. H. (2005). Sandstone vs. Carbonate petroleum reservoirs: A global perspective on porosity-depth and porosity-permeability relationships. AAPG Bulletin, 89(4), 435-445. https://doi.org/10.1306/11230404071

Embry, A. F., Klovan, J. E. (1971). A Late Devonian reef tract on Northeastern Banks Island. NWT: Canadian Petroleum Geology Bulletin, 19(4), 730-781.

Feijó, F. J. (1994). Bacias de Sergipe e Alagoas. Boletim de Geociências da Petrobras, 8(1), 149-161.

Ferm, J. B., Ehrlich, R., Crawford, G. A. (1993). Petrographic image analysis and petrophysics: analysis of crystalline carbonates from the Permian Basin, west Texas. Carbonates and Evaporites, 8(1), 90-108. https://doi.org/10.1007/ BF03175166

Figueiredo, A. M. F. (1981). Depositional Systems in the Lower Cretaceous Morro do Chaves and Coqueiro Seco Formations, and their Relationship to Petroleum Accumulations, Middle Rift Sequence, Sergipe-Alagoas Basin, Brazil. Thesis (Doctorade). Austin: University of Texas. 
Fürsich, F. T., Oschmann, W. (1986). Storm shell beds of Nanogyra in the Upper Jurassic of France. Neues Jahrbuch für Geologie und Paläontologie, 172(2), 141-161.

Fürsich, F. T., Oschmann, W. (1993). Shell beds as tools in basin analysis: the Jurassic of Kachchh, western India. Journal of the Geological Society, 150(1), 169-185. https:// doi.org/10.1144/gsjgs.150.1.0169

Gallo, V., Carvalho, M. S. S., Santos, H. R. S. (2010). New occurrence of Mawsoniidae (Sarcopterygii, Actinistia) in the Morro do Chaves Formation, Lower Cretaceous of the Sergipe-Alagoas Basin, Northeastern Brazil. Boletim do Museu Paraense Emílio Goeldi Ciências Naturais, 5(2), 195-205.

Garcia, G. G. (2012). Análise do conteúdo palinológico da Formação Morro do Chaves, Bacia de Sergipe-Alagoas e seu significado bioestratigráfico e paleoambiental. Trabalho de Conclusão de Curso. Rio Grande do Sul: Instituto de Geociências - UFRGS.

Garcia, G. G. (2016). Análise palinológica em folhelhos da Formação Morro do Chaves e implicações na evolução paleogeográfica da fase rifte da Bacia de Sergipe-Alagoas. Dissertação (Mestrado). Rio Grande do Sul: Instituto de Geociências - UFRGS.

Garcia, G. G., Garcia, A. J. V., Henriques, M. H. P. (2018). Palynology of the Morro do Chaves Formation (Lower Cretaceous), Sergipe Alagoas Basin, NE Brazil: Paleoenvironmental implications for the early history of the South Atlantic. Cretaceous Research, 90, 7-20. https:// doi.org/10.1016/j.cretres.2018.03.029

Hassan, G. S., Tietze, E., Cristini, P. A., De Francesco, C. G. (2014). Differential Preservation of Freshwater Diatoms and Mollusks in Late Holocene Sediments: Paleoenvironmental Implications. PALAIOS, 29(12), 612-623. https://doi. org/10.2110/palo.2014.016

Kidwell, S. M. (1986). Models for fossil concentrations: paleobiologic implications. Paleobiology, 12(1), 6-24.

Kidwell, S. M. (1991). The stratigraphy of shell concentrations. In: P. A. Allison, D. E. G. Briggs (Eds.), Taphonomy, releasing the data locked in the fossil record (v. 9, 211-290). Nova York: Plenum Press. (Topics in Geobiology).

Kidwell, S. M., Fürsich, F. T., Aigner, T. (1986). Conceptual framework for the analysis and classification of fossil concentrations. PALAIOS, 1(3), 228-238. http://dx.doi. org $/ 10.2307 / 3514687$
Kidwell, S. M., Holland, S. M. (1991). Field description of coarse bioclastic fabrics. PALAIOS, 6(4), 426-434. http:// dx.doi.org/10.2307/3514967

Kinoshita, M. E. (2010). Modelagem sísmica-geométrica de fácies dos carbonatos lacustres da Formação Morro do Chaves, Bacia de Sergipe-Alagoas. Boletim de Geociências Petrobras, 18(2), 249-269.

Kohonen, T. (2001). Self-Organizing Maps. Berlin: Springer-Verlag, $501 \mathrm{p}$.

Lana, M. C. (1990). Bacia de Sergipe-Alagoas: uma hipótese de evolução tectono-sedimentar. In: G. P. R. Gablagia, E. J. Milani (1990). Origem e evolução das bacias sedimentares (311-332). Rio de Janeiro: Petrobras.

Lana, M. C., Milani, E. J. (1986). A microplaca no nordeste brasileiro - Um elemento dinâmico no rifteamanto Cretacico Inferior. XXXIV Congresso Brasileiro de Geologia, n. 3, 1131-1144. Goiânia: SBG.

Lucia, F. J. (2007). Carbonate Reservoir Characterization, An Integrated Approach. Berlin: Springer Science \& Business Media. https://doi.org/10.1007/978-3-540-72742-2

Makhloufi, Y., Collin, P. Y., Bergerat, F., Casteleyn, L., Claes, S., David, C., Menéndez, B., Monna, F., Robion, P., Sizun, J. P., Rudy, S., Rigollet, C. (2013). Impact of sedimentology and diagenesis on the petrophysical properties of a tight oolitic carbonate reservoir. The case of the Oolithe Blanche Formation (Bathonian, Paris Basin, France). Marine and Petroleum Geology, 48, 323-340. http://dx.doi.org/10.1016/j. marpetgeo.2013.08.021

Mazurkiewicz, L., Mlynarczuk, M. (2013). Determining rock pore space using image processing methods. Geology, Geophysics \& Environment, 39(1), 45-54. http://dx.doi. org/10.7494/geol.2013.39.1.45

McGlue, M. M., Soreghan, M. J., Michel, E., Todd, J. A., Cohen, A. S., Mischler, J., O'Connell, C. S., Castañeda, O. S., Hartwell, R. J., Lezzark, K. E., Nkotagu, H. H. (2010). Environmental controls on shell-rich facies in tropical lacustrine rifts: a view from Lake Tanganyika's littoral: PALAIOS, 25(7), 426-438. https://doi.org/10.2110/palo.2009.p09-160r

Menezes, P. T. L., Travassos, J. M., Medeiros, M. A. M., Takayama, P. (2016). High-resolution facies modeling of presalt lacustrine carbonates reservoir analog: Morro do Chaves Formation example, Sergipe-Alagoas Basin, Brazil. Interpretation, 4(2), SE63-SE74. https://doi.org/10.1190/ INT-2014-0213.1 
Muniz, M. C., Bosence, D. W. J. (2015). Pre-salt microbialites from the Campos Basin (offshore Brazil): image log facies, facies model and cyclicity in lacustrine carbonates. In: D. W. J. Bosence, K. A. Gibbons, D. P. Le Heron, W. A. Morgan, T. Pritchard, B. A. Vining (Eds.), Microbial Carbonates in Space and Time: Implications for Global Exploration and Production (418). Londres: Geological Society, Special Publications. http://dx.doi.org/10.1144/SP418.1034

Ojeda, H. A. E., Fugita, A. M. (1976). Bacia Sergipe/ Alagoas. Geologia Regional e Perspectivas Petrolíferas. XXVIII Congresso Brasileiro de Geologia, n. 1, 137-158. Porto Alegre: SBG.

Petri, S. (1962). Foraminiferos Cretaceos de Sergipe. Boletim Faculdade de Filosofia, Ciencias e Letras da Universidade de São Paulo, 20, 5-140. https://doi.org/10.11606/issn.25263862.bffcluspgeologia.1962.121894

Ramakrishnan, T. S., Ramamoorthy, R., Fordham, E., Schwartz, L., Herron, M., Saito, N., Rabaute, A. (2001). A model-based interpretation methodology for evaluating carbonate reservoirs. Society of Petroleum Engineers. https:// doi.org/10.2118/71704-MS

Rego, E. A., Bueno, A. D. (2015). Reservoir Rocks Image Binarization: a Comparative Study Between Neural Network Method and Otsu Variance. International Journal of Modelling and Simulation for the Petroleum Industry, 9(1), 31-36.

Riccomini, C., Sant'Anna, L. G., Tassinari, C. C. G. (2012). Pré-sal: geologia de exploração. Revista USP, (95), 33-42. http://dx.doi.org/10.11606/issn.2316-9036.v0i95p33-42

Schaller, H. (1969). Revisão estratigráfica da Bacia de Sergipe/Alagoas. Boletim técnico da Petrobras, 12(1), 21-86.

Scherer, M. (1987). Parameters influencing porosity in sandstones: a model for sandstone porosity prediction.
The American Association Petroleum Geologists Bulletin, 71(5), 485-491.

Serviço Geológico do Brasil (CPRM) (2009). Carta Geológica de Arapiraca. Escala 1:250.000: Folha SC.24-X-D. Brasil: Serviço Geológico do Brasil.

Souza-Lima, W., Andrade, E. J., Bengtson, P., Galm, P. C. (2002). A Bacia de Sergipe-Alagoas: Evolução geológica, estratigráfica e conteúdo fóssil. Aracaju: Fundação Paleontológica Phoenix. 34 Edição especial.

Tavares, A. C., Borghi, L., Corbett, P., Nobre-Lopes, J., Câmara, R. (2015). Facies and depositional environments for the coquinas of the Morro do Chaves Formation, SergipeAlagoas Basin, defined by taphonomic and compositional criteria. Brazilian Journal of Geology, 45(3), 415-429. http:// dx.doi.org/10.1590/2317-488920150030211

Thompson, D. L. (2013). The stratigraphic architecture and depositional environments of non-marine carbonates from Barremian-Aptian Pre-Salt strata of the Brazilian continental margin. Thesis (Doctorade). Melbourne: Monash University, $277 \mathrm{p}$.

Thompson, D. L., Stilwell, J. D., Hall, M. (2015). Lacustrine carbonate reservoirs from Early Cretaceous rift lakes of Western Gondwana: Pre-Salt coquinas of Brazil and West Africa. Gondwana Research, 28(1), 26-51. https://doi. org/10.1016/j.gr.2014.12.005

Tietze, E., Francesco, C. (2014). Taphonomic Differences in Molluscan Shell Preservation in Freshwater Environments From the Southeastern Pampas, Argentina. PALAIOS, 29(10), 501-511. https://doi.org/10.2110/palo.2014.019

Van Der Ven, P. H., Cainelli, C., Fernandes, G. J. F. (1989). Bacia de Sergipe-Alagoas: Geologia e Exploração. Boletim de Geociencias da Petrobras, 3(4), 307-319. 